\title{
TEMPO GEOLÓGICO, SOCIEDADE E ENSINO DE GEOGRAFIA FÍSICA
}

\author{
J.C. SARAIVA JUNIOR \\ Diretoria Acadêmica de Ciências-Instituto Federal do Rio Grande do Norte \\ E-mail: joao.correia@ifrn.edu.br
}

Artigo submetido em outubro/2013 e aceito em outubro/2013

\section{RESUMO}

Este artigo analisa a necessidade de valorização do tempo geológico no ensino de Geografia Física, frente à urgência no trato das questões ambientais, amplamente, discutidas no seio da sociedade. O sentido da abordagem da geocronologia não se restringe ao conhecimento geológico per si, mas em consonância com a compreensão dos eventos que marcam a Geografia dos lugares, com uma tentativa de aprofundamento teórico no ensino básico e superior. Este trabalho discute a noção de tempo geológico na
Geografia, particularmente, pelo viés geomorfológico, biogeográfico e climatológico. O percurso metodológico é baseado em revisão da literatura e discussões realizadas com discentes e outros professores. Os resultados apontam a necessidade de maior aprofundamento nas abordagens sobre o tempo geológico no ensino de Geografia em função da perda de aprofundamento quanto à origem das paisagens geográficas.

PALAVRAS-CHAVE: Tempo Geológico, Sociedade, Ensino de Geografia Física.

\section{GEOLOGICAL TIME, SOCIETY AND PHYSICAL GEOGRAPHY TEACHING}

\begin{abstract}
This article analyzes the need of appreciation of the Geologic time in Geography Physical teaching, due to urgency about the environmental subjects, largely discussed in society. The sense of the geochronology's approach is not only the geological knowledge per si, but its application on the basis of the events' understanding which marks the Geography of places, a try of theoretical deepening at high school and at university. This research discusses the geological time notion in
\end{abstract}

Geography, particularly in geomorphologic, biogeographic and climatological way. The methodological course is based in a review of the literature and discussions with other students and teachers. The results show the need of a large deepening in approaches about the geological time in Geography teaching due to the loss of depth as the origin of geographical landscapes.

KEYWORDS: Geological Time, Society, Physical Geography Teaching. 


\section{TEMPO GEOLÓGICO, SOCIEDADE E ENSINO DE GEOGRAFIA FÍSICA}

\section{INTRODUÇÃO}

O ensino de Geografia vem conquistando espaço, nas últimas décadas, particularmente, pela importância que a ciência geográfica assumiu no âmbito das questões ambientais e(qui)vocadas neste início de século XXI. Mudanças climáticas, utilização das fontes alternativas de energia, movimentos de massa e erosão costeira são alguns dos temas de destaque na sociedade contemporânea e que estão, intimamente, relacionados aos conteúdos geográficos, principalmente, aqueles que tratam das potencialidades e limitações das paisagens ao uso social.

Mas, o que seriam as paisagens senão resultados da superposição de tempos (histórico e geológico) e que estão em constantes mudanças, ainda que difíceis de identificar? As impressões existentes nas paisagens, como formas, em perpétua transformação, abrigam intencionalidades, contradições e processos naturais, entre outras categorias. No entanto, muitas abordagens feitas por geógrafos (sobretudo, na sala de aula) restringem-se à análise das paisagens atuais, apropriadas e modificadas segundo os interesses da sociedade. Essa dimensão histórica, que possui na obra de Milton Santos um importante referencial teórico, prevalece nos livros didáticos de Geografia, necessitando, no entanto, ser revisado por não considerar o tempo da natureza ou tempo geológico nas diversas situações cotidianas.

Nesse ínterim, os resultados de milhões de anos de interação entre os elementos da natureza e energias existentes nos sistemas ambientais são relegados à descrição do meio físico, limitando o avanço das discussões acerca da gênese das paisagens e dos recursos naturais, em particular, na ciência geográfica.

Embora a magnitude do tempo geológico não seja discutida amplamente, sua influência está intimamente associada ao cotidiano da sociedade, seja em um evento catastrófico ou em uma visita a um museu geológico, ou ainda a um geopark. Por que haveria, então, da Geografia minimizar tais discussões que se referem a evolução e organização do meio natural, sob o pretexto de fugir da análise de produção social do espaço geográfico? Haveria um espaço geográfico sem base física, inclusive desprovida de fenômenos naturais?

Partindo dessa problemática, o objetivo deste artigo é discutir como se dão as abordagens do tempo geológico no ensino de Geografia contemporâneo, apresentando as concepções do mesmo, identificando a sua relação ímpar com as subáreas do ensino de Geografia Física (Geomorfologia, Climatologia e Biogeografia), além da relação com a Geografia Humana e apresentando, ainda que de forma incipiente, o diálogo protagonizado pelo quadro de crise socioambiental do século XXI e a geocronologia.

A pesquisa foi realizada através de levantamento bibliográfico disponível acerca das temáticas tratadas e discussões em diversos espaços (sala de aula, encontros de estudantes), quanto à necessidade urgente de abordar o tempo geológico em toda sua magnitude, inclusive, com a ação da sociedade como integrante da escala geocronológica. 
Dado o caráter polissêmico do substantivo tempo, analisaram-se as concepções de tempo geológico, ou melhor, a organização do conceito, dentro de uma perspectiva histórica. Este trabalho não contempla a melhor forma de discutir o tempo geológico no ensino de Geografia, mas traz indicativos de quais conteúdos podem ser aprofundados em uma abordagem que dialogue com a superposição de tempos na formação das paisagens.

Destaca-se aqui, que outra área do conhecimento presente no ensino básico, como a Biologia, também apresenta suas contribuições ao conjugar os verbos que apontam a evolução da vida, seja ela microbiana, megafauna e cobertura vegetal. Contudo, em Geografia, encontramos uma abordagem ímpar que coloca em relevo a relação sociedade-natureza, mediada pelo tempo! Mas de que tempo estamos falando?

A compreensão satisfatória da evolução do planeta perpassa pelo entendimento das mudanças observadas nos ambientes e nos seres vivos. Essa premissa nos remete à ideia de tempo, como conceito balizado pela Física. O tempo geológico (ou geocronologia) acompanhou o desenvolvimento da própria ciência como campo sistematizado do saber social. Esse mesmo tempo geológico, associado a processos específicos, convida-nos a refletir acerca da nossa condição/ação na esfera reflexiva da sobrevivência humana.

Este artigo discute inicialmente a noção de tempo e do surgimento da noção de tempo geológico na história das ciências e da Geografia. Na sequência, apresenta-se as principais subáreas da Geografia (Física) que necessitam do tempo geológico para compreensão da problemática da evolução dos elementos paisagísticos. Finalmente apresenta-se a importância dada ao tempo no ensino de Geografia e a exemplificação de alguns conteúdos fortemente marcados pela superposição dos tempos (natural e social). E por falar em tempo, como surgiu tal categoria?

\section{Tempo(s) e Geografia(s): considerações iniciais}

$\mathrm{Na}$ antiguidade, no panteão mitológico politeísta, as civilizações clássicas já atribuíam ao substantivo tempo, a personificação de uma entidade capaz de controlar, efetivamente, os eventos cósmicos até os destinos dos indivíduos, e consequentemente, das sociedades. Segundo Bulfinch (2002), os gregos atribuíram a Chronus (tempo) o fim de todas as coisas criadas, já que o tempo destrói tudo que ele mesmo cria. A evocação da ideia de tempo, entre as civilizações clássicas, sinaliza a construção de um conceito que remete ao desenrolar dos fatos em um intervalo em que se sucedem fenômenos. Para as sociedades agrícolas, como os egípcios, a noção de tempo estava, intimamente, associada à mudança de comportamento dos rios. Cheias e períodos de estiagem preconizavam as noções de intervalos, que aperfeiçoados séculos seguintes, viriam a ser denominados calendários.

Com o avanço do cristianismo e sua imposição ao longo de toda a Idade Média, a noção de tempo passou a ser vinculada à criação divina, atribuída ao grande artífice que modelou o planeta e a vida ao longo de 7 dias. Segundo a narrativa bíblica, a criação ocorreu em etapas, com uma evolução gradual dos elementos criados, por exemplo, a delimitação entre terras secas e águas, no terceiro dia, e luzeiros para iluminar o dia e a noite. A criação, ocorrendo em um 
intervalo de sete dias, também remete a uma cronologia dos eventos que se sucederam em um tempo profundo, embora essa noção temporal apresente-se em diferentes grandezas escalares.

Com o alvorecer das ciências e o avanço da razão sobre as questões ligadas à fé, contextualizado no limiar entre a Idade Média e a Moderna, o tempo passou a ser discutido em uma perspectiva que permitia medir a separação ou duração das coisas mutáveis. Pesquisadores das ciências naturais, em particular da Física, agregaram ao conceito tempo o ordenamento de sequências, estabelecendo conexões entre passado, presente e futuro, alicerçando o princípio de causalidade como um dos axiomas do método científico.

No contexto de concretização das ciências naturais, por volta do século XVIII, a noção de tempo geológico foi sendo construída e consolidada, sobretudo enfocando a organização dos sistemas naturais. Teorias diversificadas tentaram determinar a idade da Terra, com variações inerentes a cada religião, a exemplo da judaica ao afirmar a idade de 3.761 a.C ou ainda o contexto de elaboração do calendário bizantino que atribuiu por volta de 5.808 a.C a data de origem da terra.

No entanto, foi em meados do século XIX que as contribuições do geólogo James Hutton, ao propor o Princípio do Atualismo, colocaram em xeque, as concepções catastrofistas e dogmáticas até então vigentes sobre a origem dos complexos litológicos emersos, dos oceanos, e a magnitude do tempo geológico. A contribuição de Hutton foi tão significativa que seguidores de suas teorias passaram a não somente adotá-la, mas melhorar os enunciados. Merecem destaque as contribuições de Charles Lyell e John Playfir ao anunciar que o passado é interpretado à luz do presente, necessitando o pesquisador investigar os processos atuantes na superfície (EICHER, 1969).

Ao longo do século $X X$, os avanços nas pesquisas sobre radioatividade e outras especificidades dos elementos químicos proporcionaram a consolidação de técnicas efetivamente capazes de realizar a datação (embora aproximada) dos materiais geológicos, inferindo idades aos eventos que marcaram a superfície terrestre ao longo de sua história natural.

A construção da noção de tempo geológico, tal qual a conhecemos hoje, é fruto de um longo processo de debates filosóficos e experimentais que culminaram com tentativas de explicações baseadas em elementos ora dogmáticos, ora fundamentados, hierarquicamente, por evidências geológicas e biológicas, conclusivas na existência de um tempo profundo. Desse modo, a complexidade do tema é um convite a refletirmos sobre a nossa situação, dentro da história terrestre.

A Geografia, ao inserir a geocronologia no ensino, parece ter sido agregada apenas aos conteúdos que tratam das rochas e do relevo. Uma noção de tempo profundo, sobre o qual se desenrola o novelo da história natural/social das paisagens, ficou limitada a "decorar" alguns intervalos mais utilizados como o Quaternário, sem uma preocupação com a perspectiva de evolução. 


\section{RESULTADOS E DISCUSSÕES}

No alvorecer de sua sistematização, a Geografia foi fortemente influenciada por naturalistas preocupados em descrever, exaustivamente, os componentes das paisagens, tomando por base uma perspectiva isolada, balizada pelo Positivismo, pretensamente neutro, servindo quase que exclusivamente aos interesses das nações imperialistas.

Segundo Bertolini e Valadão (2009), a Geografia teve que lidar, desde o início, com as duas noções de tempo (geológico e histórico), sobretudo quando as abordagens referiam-se ao relevo. Cabe destacar que foi através da Geomorfologia que se deu a incorporação da noção de tempo geológico na Geografia.

As obras de importantes pesquisadores geógrafos, como Alexander Von Humboldt, descrevem os componentes naturais, realizando incipientes alusões acerca da temporalidade responsável pela geração das rochas, formas de relevo e ecossistemas. A ação da sociedade era considerada ínfima diante da magnitude do tempo geológico. Os objetivos dos trabalhos eram descrever as características do meio natural, que poderia ser apropriado, conforme a lógica da expansão imperialista, evidente no final do século XIX.

Tratando-se da Geomorfologia, no início do século XX, a obra de William Morris Davis representou um importante divisor de águas na abordagem teórico-metodológica da Geomorfologia, definindo etapas na evolução do relevo que se assemelhavam às fases antropomórficas (juventude, maturidade e senilidade). Tem-se, nesse contexto, um importante avanço na identificação da importância do tempo geológico na analise geográfica. Para Davis, as diferentes fases de evolução geomorfológica aconteciam em um intervalo de tempo que ultrapassava os milhões de anos.

Se tomarmos como exemplo o caso brasileiro, a obra davisiana marcou, profundamente, os trabalhos de geomorfólogos brasileiros nos anos 1930 até 1950. Nesse contexto, destacam-se os trabalhos de Emanuel de Martonne: Problemas Morfológicos do Brasil Tropical Atlântico I e II, que discutem a questão das superfícies de erosão e ação de glaciares sobre o Estado de São Paulo. Nas décadas seguintes, preocupações genéticas foram incorporadas aos trabalhos de geomorfologia, a exemplo da grandiosa obra de Aziz Nacib Ab 'Saber, que evidencia a importância da compreensão da dinâmica Quaternária na gênese e evolução do relevo (VITTE, 2011).

Ab'Saber (1968) alertava, continuamente, sobre a importância de preservação das heranças paisagísticas que atestam a evolução dos sistemas naturais. O percurso metodológico desenvolvido por ele agregava informações referentes ao tempo geológico recente (Quaternário) e o condicionamento que o relevo oferecia na ocupação das paisagens, situação detalhada, principalmente, no estado de São Paulo.

Em Biogeografia, o entendimento da diversificação das espécies, em particular da cobertura vegetal, encontra no tempo geológico as bases para a compreensão dos cenários pretéritos cuja expressão era marcada fortemente por condições ambientais diferenciadas. No Brasil, a aplicabilidade de proposições teórico metodológicas como a Teoria dos Refúgios encontrou na obra de $A b$ 'Saber $(1979,2003)$ um importante celeiro de conceitos que trata da dinâmica fitogeográfica, a exemplo da discussão sobre a expansão e retração de cerrados e caatingas no Quaternário. As mudanças climáticas que se sucederam intensamente nos últimos dois milhões de anos desencadearam maiores ou menores taxas da umidade do ar (SILVA, 2011). 
Essa dinâmica climatológica pretérita registrou em fósseis e sedimentos os resultados das oscilações climáticas cenozóicas. Os paleoclimas do Brasil foram amplamente estudados também por $A b^{\prime}$ Saber em praticamente toda a sua trajetória intelectual, como forma de explicar a atuação dos processos geodinâmicos externos responsáveis pela esculturação das paisagens tropicais. Outros pesquisadores como Bigarella (2003) e Salgado-Labouriau (1994) deram importantes contribuições no cenário da produção acadêmica que discute a evolução dos sistemas naturais materializadas na distribuição da vegetação na superfície.

No âmbito das pesquisas ambientais, após a consolidação das conferências mundiais sobre o meio ambiente (da década de 1970 em diante), a Geografia brasileira viu-se invadida pela produção avassaladora de pesquisas sobre a dinâmica ambiental, destacando a contribuição da Geomorfologia no entendimento da geração de áreas de risco em meio urbano. Segundo Vitte (2011), a obra de Jurandyr Ross, na década de 1990, representou um salto qualitativo nas pesquisas geomorfológicas, porém paradoxal, porque elucida o papel das morfologias no contexto de degradação, mas uma indiscutível perda das reflexões sobre a gênese do relevo.

Seria coerente, então, os geógrafos optarem pela rejeição ao aprofundamento teórico concernente às pesquisas relacionadas à gênese do relevo, destacando a inexorável e indispensável magnitude do tempo geológico na compreensão da origem e evolução das paisagens?

De acordo com as orientações dos documentos norteadores do Ensino Básico no Brasil, a Geografia, deve contribuir na compreensão da escala de tempo(s) para situar a humanidade no processo de transformação da natureza.

\section{Tempo geológico e PCNs: competência da Geografia?}

A Geografia é um dos principais componentes do Ensino Básico a discutir o resultado da superposição de tempos sobre a superfície terrestre, frente a outras áreas do conhecimento. Nos Parâmetros Curriculares Nacionais, encontramos, em diversos momentos, alusões à função da Geografia, que deve fomentar o aluno para reconhecer as dinâmicas existentes no espaço geográfico. Conceitos como natureza e ambiente integram as concepções que embasam as metodologias do Ensino de Geografia, além da paisagem como categoria de análise do espaço geográfico.

Numa perspectiva de análise sob o viés naturalista, as paisagens representam heranças de processos fisiográficos e biológicos de atuação antiga, mas remodelados por mecanismos de atuação recente (AB'SABER, 2003). Tais paisagens resguardam heranças morfoestruturais de até várias centenas de milhões de anos (PEULVAST; CLAUDINO SALES, 2002). Nesse sentido, as paisagens são identificadas segundo a inserção das análises do tempo geológico, numa amplitude geológica que tem origem em mecanismos como a tectônica de placas e mudanças climáticas.

Sob o viés histórico, o recurso analítico paisagem é identificado segundo Santos (1988), como resultado das condições técnicas e econômicas que denunciam tempos diferentes de apropriação social, transformando continuamente a primeira natureza em segunda natureza. Para Santos (1988) não há possibilidade de falarmos em uma Geografia Física que não inclua a sociedade, pois esta já transformou em ecúmeno a superfície terrestre. A crítica feita pelo autor 
não exclui as análises das leis naturais, mas sugere o avanço das abordagens geográficas ao qualificar a natureza herdeira do natural e aquela que provém do artifício.

Bertrand (2007), em sua clássica obra Paisagem e Geografia Física Global, afirmou que a paisagem "não é a simples adição de elementos geográficos disparatados", mas uma combinação dinâmica e instável de elementos físicos, biológicos e antrópicos. Para Bertrand (2007) estudar a paisagem é antes de tudo apresentar um problema metodológico, pois envolve o tratamento das escalas têmporo-espaciais, para além da paisagem natural.

Assim, a linguagem geográfica expressa os diferentes fenômenos, cabendo ao professor de Geografia, dentro de seu fazer pedagógico, estimular a reflexão da realidade territorial originada a partir da apropriação do meio geográfico pela sociedade, para muito além da opção existente nos livros didáticos e veículos de comunicação midiáticos, que doutrinam, regularmente, os segmentos sociais de forma sensacionalista acerca de eventos catastróficos ou anda superando a estereotipização presente no Ensino Superior com a Geografia Humana e Geografia Física. No ensino básico somos professores de Geografia!

Os fenômenos geográficos presentes fortemente no cotidiano dos estudantes apresentam diferentes temporalidades que se sobrepõem e se materializam nas paisagens. Os PCNs de Geografia apontam a necessidade do estímulo a uma leitura crítica da paisagem inclusive apontando a dimensão tempo no saber geográfico. Assim, o tempo da natureza que pode ser calculado em milhões de anos e o tempo histórico, apresentam processualidades identificáveis e por vezes confusas.

O que dizer, por exemplo, dos espaços litorâneos ocupados e que sofrem intensa degradação ambiental? A dinâmica costeira continua a retirar e depositar sedimentos que associada aos processos de apropriação originam cenários intensamente em meio ou menor grau de ocupação, também ao sabor do cumprimento da legislação específica sobre tais áreas. $E$ as análises sobre espaços destinados a conservação dos recursos naturais, como o Parque das Dunas em Natal/RN, que agregam processos naturais e diferentes formas de uso pela sociedade, inclusive originando incipientes áreas de risco no entorno do parque, por acaso a sociedade deu origem aos campos dunares? Não seria possível realizarmos uma abordagem de pesquisa sobre a origem e transformação dessa paisagem segundo o tempo geológico e tempo das técnicas?

Para uma breve demonstração das abordagens realizadas pelos livros didáticos de Geografia, quanto aos tempos da natureza, investigações foram realizadas por Silva (2004), que identificou várias formas de discutir natureza transitando entre as noções de recurso natural ou ainda de natureza externa aos seres humanos. Vale ressaltar que as pesquisas de Silva (2004) identificaram que em praticamente todos os livros existem textos fundamentados em notícias largamente discutidas pela mídia sensacionalista, cabendo aos autores dos livros e principalmente aos docentes de Geografia cuidados no momento de selecionar o livro e elencar tais conteúdos em sala de aula.

No âmbito das pesquisas feitas no Ensino Superior, particularmente em Geomorfologia, Vitte (2011) aponta para a elevada produção de pesquisas sobre a apropriação e compartimentação do relevo, enquanto as pesquisas preocupadas com a genética das paisagens 
geomorfológicas vêm sendo realizadas, magistralmente, por geólogos. Claudino Sales (2004) já apontava a possibilidade de tentativa de reconstrução das paisagens a partir da tectônica de placas que modificou sensivelmente a compreensão sobre o funcionamento da geodinâmica interna. Evidentemente, só é possível incorporar o entendimento da paleogeografia global através da compreensão efetiva da geocronologia.

Nos cursos de formação dos professores de Geografia, as tendências metodológicas, fortemente influenciadas pela Geografia Crítica, não consideram relevantes tais conceitos, frente ao compromisso de seus seguidores em discutir a produção social do espaço balizado pela dialética marxista. No entanto, torna-se oportuno questionar se nesse contexto, os geógrafos físicos paradoxalmente acomodaram e eliminaram o aprofundamento teórico-metodológico de suas especialidades?

Como um círculo vicioso, se, no Ensino Superior, não encontramos espaço para a compreensão do tempo geológico, nas pesquisas o mesmo encontra-se restrito aos conteúdos de Geologia e Geomorfologia; assim, os licenciandos tendem a abnegar tal conhecimento, em função de uma formação que prioriza análises instantâneas que possuem a devida importância, mas não satisfazem a difusão e o estímulo aos estudantes dos níveis básico e superior em buscar tais conhecimentos e identificá-los no cotidiano.

Alguns trabalhos apontam a fragmentação do conteúdo de Geociências (incluindo a geocronologia) nas disciplinas de Ciências e Geografia nas séries iniciais do Ensino Fundamental destacando a ineficiência de tais abordagens (BACCl, et al, 2009). Ainda segundo esses autores, o Ensino de Geociências apresenta enorme contribuição na formação de cidadãos responsáveis. Reitera-se aqui a concordância com tal afirmação, seguindo a proposta de Bacci,

\begin{abstract}
Se considerarmos a escala de tempo geológico, a existência da espécie humana é ínfima diante das transformações sofridas pelo planeta. $O$ conhecimento deste fato pode não ter um impacto imediato, mas à medida que nos damos conta do poder de transformação da nossa espécie e da velocidade com que isso tem ocorrido no planeta, ele pode desencadear um processo reflexivo sobre o comportamento da nossa sociedade e sobre o nosso futuro. Ao estudar o tempo geológico, o aluno tem estimulada uma maior criticidade em relação à origem e formação dos bens naturais $e$, portanto tem a possibilidade de fugir do antropocentrismo e a oportunidade de mudar a atitude predominantemente predatória (BACCl et al, 2009, p. 3462, grifo nosso)
\end{abstract}

Ora, se o objetivo do ensino de Geociências é estimular a formação de cidadãos com capacidade intelectual crítica desenvolvida, a luta pelo fim do antropocentrismo conta com uma área do conhecimento detentora de tais argumentos: a Geografia.

Nesse sentido, defende-se aqui a ideia de que a Geografia possui um corpo teóricometodológico suficientemente consolidado para discutir, com propriedade, o tempo geológico como conteúdo de alta importância no estudo das paisagens e dos elementos constituintes, como, por exemplo, a formação e exploração dos recursos naturais. Não há, portanto, necessidade da criação de uma disciplina de Geociências no ensino básico, defendida por alguns geólogos provavelmente fundamentados na conquista de mercado de trabalho. 
A Geografia deve proporcionar a leitura da paisagem como percurso metodológico de ensino para que o aluno possa observar, descrever, comparar e analisar fenômenos do cotidiano, desenvolvendo habilidades cognitivas, hierarquicamente, mais complexas (BRASIL, 1998). Ainda segundo Bonito et al (2005), é possível estimular a compreensão de uma cartografia quadridimensional dos elementos geológicos e morfológicos da paisagem, ao sermos capazes de mensurar a largura, altura, altitude e cronologia do modelado da superfície.

Em diversos exemplos do cotidiano, encontramos situações que remetem à_geocronologia dos processos formadores das paisagens e processos naturais que continuam ocorrendo mesmo em meio a uma sociedade densamente informatizada e tecnificada. A influência do ciberespaço nas relações sociais não é capaz de mascarar a imponência e devastação dos processos geológicos quando atinge parcelas da litosfera densamente ocupadas, a exemplo dos tremores de terra no Haiti, em 2010, ou tsunamis que atingiram as Ilhas Sumatra no Oceano Índico, em 2004. Embora a sociedade volte-se progressivamente para as redes sociais e a utilização da técnica na criação de espaços artificializados, habitamos na superfície e dependemos da estabilidade que a crosta apresenta, mesmo habitando no Japão (referência na construção de edificações dotadas de estruturas de antisismicidade).

Alguns exemplos de conteúdos tipicamente geográficos remetem a noção de tempo geológico para uma compreensão mais efetiva, a saber:

\section{Elevação do nível dos mares e aquecimento global}

As linhas de costa apresentam características de ambientes marcados fortemente pela instabilidade frente à ação das marés, ondas e ação eólica. A configuração primordial da zona costeira brasileira, por exemplo, está intimamente relacionada à última fissão dos continentes (segmento Gondwana, da Pangeia) ao final do Cretáceo, por volta dos 80 m.a.

Concomitante à expansão do assoalho oceânico e afastamentos das placas sul-americana e africana, as flutuações climáticas, ao longo do Paleógeno/Neógeno (antigo Terciário) e particularmente no Quaternário, provocaram avanços e recuos ao longo de toda a costa brasileira, fatos evidenciados pelas diferenciações na extensão da plataforma continental e exumação de paleomangues, em diversos pontos do litoral brasileiro, como em Aquiraz no Ceará, praias de São Paulo e do Rio Grande do Sul, apresentando alguns dos vestígios dessas mudanças que imprimiram formas significativas no modelado costeiro do Brasil.

As variações do nível do mar, impulsionadas, sobretudo pela eustasia, ocorreram em períodos geológicos que a sociedade ainda não havia se organizado. O nível do mar passou por inúmeras fases de transgressão e regressão, inumando áreas correspondentes a recortes espaciais, inclusive ocupadas por casas de veraneio e equipamentos turísticos e que em diversos momentos vem sofrendo avanço das ondas marinhas.

Segundo o Relatório de Erosão e Progradação do Litoral Brasileiro, publicado pelo Ministério do Meio Ambiente, em 2009, diversas paisagens litorâneas estão sofrendo processos erosivos acelerados, com déficit de material sedimentar, ocasionando, em muitos casos, a 
destruição quase completa da faixa praial, a exemplo de Sepetiba (RJ) e Iparana (CE). As ocupações irregulares modificaram significativamente a dinâmica costeira, mas nesses lugares o recuo da linha de costa está erroneamente, associado à elevação do nível dos mares, pelo aquecimento global que alguns acreditam estar em curso.

O alarmismo, fortemente presente na mídia sensacionalista, desencadeou pânico generalizado ao falar de uma possível elevação no nível dos mares. Constata-se, nos últimos anos, a concretização de um poderoso meio de doutrinamento provocado pelos meios de comunicação e indústria cinematográfica, quando o assunto é desastre natural. Essa ferramenta torna-se mais poderosa que os professores em sala de aula!

O contingente de estudantes que, obrigatoriamente, cursam Geografia não tem direito a espaços de reflexão que possam contrapor as argumentações sustentadas pela superficialidade teórica e de negação das particularidades dos lugares? Se não formos competentes para diferenciar processos globais de problemas pontuais, qual a nossa função enquanto profissionais?

\section{Geoparks, Sítios Paleontológicos e Unidades de Conservação}

Em vários pontos do Brasil e do mundo, segmentos da sociedade preocupam-se em delimitar espaços que preservem a história natural do território e constituam-se espaços educativos que contribuem com o entendimento da geodinâmica atuante em um tempo profundo e que deixou vestígios imponentes na paisagem, como o Geopark Araripe na área limítrofe entre o Sul do Ceará e o Noroeste de Pernambuco.

O Geopark Araripe é a maior exumação de rochas e fósseis do Cretáceo, constituindo-se patrimônio da humanidade, porque denuncia um fragmento da monumental evolução terrestre. Se gestores e comunidade local não se sensibilizarem pela importância e riqueza científica que tais elementos representam para a humanidade, como concretizar propostas de uso sustentável desse espaço?

A criação das SNUCs (Sistemas das Unidades de Conservação) convida a sociedade a refletir sobre as heranças das paisagens naturais (AB'SABER, 2003). No entanto, quando se discute patrimônio natural, na maioria dos casos em Geografia, contraditoriamente reduz-se à perspectiva de recurso natural.

A história natural do planeta, preservada nas rochas, coberturas pedogenéticas e feições geomorfológicas, encontra, nas SNUCs, importantes centros de difusão das geociências, cuja expressão pode ser discutida em verdadeiros laboratórios vivos. A contribuição da temporalidade geológica é evidenciada nos argumentos de delimitação e concretização das Unidades de Conservação, além da manutenção da biodiversidade e preservação dos mananciais.

\section{Exploração de recursos naturais}

Os elementos do meio físico e suas interações de fluxos de matéria e energia são responsáveis pela origem de materiais, que convencionalmente foram denominados recursos 
naturais. Segundo Santos (1998), a natureza é transformada (também denominada Segunda Natureza) para suprir as necessidades da sociedade. Nesse sentido, a apropriação dos recursos naturais atende a demandas específicas, geralmente situadas em um determinado contexto histórico (VENTURI, 2006). No conjunto de tipologias que qualificam os recursos naturais, destacam-se os recursos energéticos, considerados fundamentais para o desenvolvimento de qualquer nação.

Tomemos como exemplo a exploração petrolífera da bacia potiguar no Nordeste brasileiro: essa importante depressão intracratônica foi originada no contexto dos eventos tectônicos que culminaram com a separação total entre os continentes sul-americano e africano. Os mecanismos deposicionais incluíram corridas de lama, deposição fluvial e sedimentação marinha que atulharam a bacia potiguar, subdividida nas porções onshore e offshore, apresentando destaque na produção petrolífera no Brasil. Ao serem abordados os conteúdos, na Educação Básica, sobre a matriz energética brasileira, apresenta-se o petróleo como um recurso não renovável. No entanto, pouca ênfase é dada ao tempo de formação do recurso. Mas é sabido que a compreensão da temporalidade do recurso não renovável perpassa pelo tempo geológico.

Qual a idade mínima de formação do petróleo? Quais as tipologias de hidrocarbonetos encontradas nos ambientes sedimentares e qual a relação entre a concentração de carbono e o tempo de formação? Destaca-se ainda a presença de jazidas carboníferas no subsolo brasileiro originadas da deposição e compactação de pacotes sedimentares ricos em matéria orgânica, amplamente distribuídos na região Sudeste brasileira. Várias dessas questões são pertinentes à discussão geográfica das fontes de energia por representarem fatores importantes nas abordagens do ensino de Geografia.

As escalas adotadas nessa abordagem iniciam numa escala de curto tempo que faz menção ao uso do petróleo, gás natural e carvão mineral pela sociedade, mas também destacariam a origem de tais recursos e sua distribuição sobre a terra.

\section{Sismicidade, ensino de Geografia e sociedade}

Há décadas, difundiu-se a ideia de que estaríamos livres de abalos sísmicos, vantagem locacional sustentada pela centralidade que o território brasileiro apresenta no seio da Placa Sul Americana. Porém, eventos sísmicos de magnitude e frequência variadas ocorrem, diariamente, por toda a plataforma sul americana. A gênese dos terremotos, em território brasileiro, está intimamente relacionada à reativação de falhas existentes em todo o território brasileiro e aos processos tectônicos globais. Tremores acontecem com frequência em áreas densamente ocupadas, a exemplo de Sobral (CE), João Câmara (RN) e Montes Claros (MG), que apresentam um longo histórico de eventos sísmicos.

Esses processos de atividade sísmica recente integram o conceito de neotectônica, definindo-a como eventos tectônicos jovens, responsáveis por modificações significativas da morfologia atual (LIMA, 2000). Embora a manifestação das ondas sísmicas seja praticamente instantânea, a tensão acumulada nas rochas ocorre em uma escala temporal que só podemos compreender se aprofundarmos a noção de tempo geológico! 
Se não discutirmos esse processo, na perspectiva do tempo geológico, estaremos imprimindo superficialidade nas aulas, ou será que pânico e perdas econômicas não nos interessam? E a população, não merece esclarecimento acerca dos processos genéticos de tais eventos? Reitera-se que a Geografia é a disciplina escolar que possui condições magistrais de abordagem primordial dessas peculiaridades, afinal, segundo Monbeig (1945) "não é o geógrafo que estuda as relações complexas dos meios naturais e dos grupos humanos, em sua localização"? .

\section{Quinário e Geografia: temporalidade marcada pela técnica}

Esse conceito ganhou notoriedade na década de 1920, valorizando a ação humana na apropriação e reconstrução da natureza, fatos profundamente marcados pela adoção de técnicas que deram origem a resíduos distribuídos por praticamente toda a superfície terrestre, denominados depósitos tecnogênicos.

Como resultado da ação humana, os depósitos tecnogênicos constituem os novos vestígios da evolução geomorfológica, compreendida por vários pesquisadores como profundamente marcada pelo antropismo, conduzindo a aceleração dos processos (ROSSATO; SUERTEGARAY, 2000).

Ora, se vivenciarmos uma nova etapa na dinâmica geomorfológica, quais as fases ulteriores? Poderíamos refletir sobre a dinâmica geomorfológica apenas no tempo presente? Necessariamente, precisamos relacionar os conteúdos entre os tempos geológico e histórico, particularmente quando nos referirmos aos processos morfogenéticos.

Nos centros urbanos, a artificialização da paisagem inclui a substituição de superfícies pedogenéticas e paleocanais de drenagem, produzindo, na maioria dos casos, até uma falsa impressão de que o tempo geológico não atua mais sobre tais sistemas. Mas, dependendo da escala de análise, a dissecação e (re)orientação da drenagem continuam ocorrendo, sobretudo nos táxons denominados pelo IBGE (1995) como sendo Regiões e Unidades Geomorfológicas.

Assim, como incluir a ação da sociedade, enquanto poderoso agente geomorfológico, em um contexto de consenso entre a comunidade científica da adição do Quinário na tabela geocronológica, se não compreendermos as bases da seqüência pretérita?

\section{Paisagens, tempos, processos e ensino de Geografia}

As condições de interpretação da realidade, como um todo, na verdade, dependem do caráter metodológico presente nas pesquisas desenvolvidas pelos graduandos (orientados por professores...) ou pelas abordagens desenvolvidas em sala de aula. Se abnegarmos o entendimento da contribuição do tempo geológico e sua influência na paisagem, por falta de domínio do assunto, ou por opção política, estaremos oportunizando aos estudantes, independentes de qual nível de formação estejam, um ensino de qualidade, capaz de estabelecer um diálogo entre as diversas variáveis? 
Tremores de terra, erosão costeira e superaquecimento dos centros urbanos que são colocados exclusivamente (e muitas vezes, absurdamente) como provocados tão somente pela ação humana, não seriam meios de falsear/mascarar a origem dos fenômenos? Enquanto profissionais comprometidos com o ensino de Geografia coerente, deveríamos nos dedicar a entender as explicações baseadas em métodos científicos capazes de fornecer o arcabouço teórico e empírico que elucidam, com destreza, acerca das origens dos processos que tanto influenciam a vida humana.

Silva (2004) defende que não interessa a discussão especializada e detalhada do quadro físico. Como não interessa ao alunado entender a formação das paisagens que o cercam sem abordagem das especificidades? Ao aluno interessa sim a especificidade do meio físico onde habita e que exercem influência sobre sua vida.

A exemplo do desencadeamento dos processos erosivos que independem das formas de uso e ocupação, a geodinâmica externa sempre atuou na superfície terrestre, antes mesmo da presença da sociedade. É importante destacar que não se negligencia aqui a atuação da sociedade sobre os sistemas naturais e reitera-se que os processos erosivos são acelerados, sobretudo em função do desmatamento e substituição da cobertura vegetal nativa por culturas que não apresentam competência na amenização do impacto mecânico da precipitação pluvial.

O tempo geológico deveria ser abordado com clareza no ensino de Geografia. Quando conseguirmos dialogar com a realidade, sem necessidade de separação dos conteúdos (Física e Humana), poderemos auxiliar no desenvolvimento de competências suficientes que conduzissem ao domínio da abstração.

Nas pesquisas desenvolvidas por geógrafos brasileiros, a desatualização dos dados é tão evidente que a Comissão Internacional de Estratigrafia, suprimiu a denominação Terciário da tabela geocronológica, adotando as denominações Paleógeno e Neógeno, desde 2004. No entanto, quase uma década depois, as pesquisas em Geomorfologia ou ainda os trabalhos desenvolvidos por geólogos carecem de atualizações, denunciando a negligência para com o assunto.

\section{CONSIDERAÇÕES FINAIS}

Os defensores da inserção de conteúdos das Geociências no ensino básico como disciplina autônoma simplesmente defendem a incompetência da Geografia no trato desses conteúdos. No entanto, destaca-se aqui que a Ciência Geográfica possui condições teórico-metodológicas suficientes para discutir com propriedade o tempo geológico e os processos geodinâmicos, estimulando a formação de estudantes com visão integrada e ampla da realidade atual.

Cabe aos geógrafos lutarem por mais espaço e valorizar determinados conteúdos que transitam entre a necessidade e o abandono quando se trata do ensino de Geografia. Inserir o tempo geológico nas análises geográficas (em campo ou em sala) não é discutir Geologia! Geografia Física não é Geologia, embora haja estreitos laços entre esse conhecimento e aquele. No entanto, compreendemos que as diferentes escalas temporais (geológica e histórica) 
sobrepõem-se na paisagem e devem ser dissecadas como exercício de investigação e base da compreensão da sustentabilidade e da manutenção da vida.

A formação dos professores de Geografia precisa ser melhorada, evidenciado as abordagens de um tempo geológico que está presente no cotidiano do estudante e que ele mesmo é um elemento fundamental na escala geocronológica, capaz de apropriar-se dos sistemas naturais e modificá-los sensivelmente.

Semelhante aos conteúdos de Cartografia, que devem estar presentes em qualquer conteúdo geográfico, o tempo geológico assim também pode ser explorado, possibilitando aos estudantes o desenvolvimento de competências amplamente defendidas e argumentadas nos Parâmetros Curriculares Nacionais.

O espaço geográfico é construído a partir da imposição da sociedade sobre a natureza. Tempos diferentes (no sentido linear) são testemunhos de mudanças oriundas pela ação da geodinâmica ou ainda do consumo de recursos naturais e das paisagens. Faz-se mister abordar esse espaço em sua totalidade, com uma postura crítica que dialogue com as diversas áreas do conhecimento.

A crítica feita aos estudos geográficos da natureza em si seria totalmente coerente se a finalidade maior de tais estudos não fosse o conhecimento da superfície terrestre em sua totalidade. Ao serem identificados os mecanismos genéticos das paisagens, a construção de propostas de uso sustentável torna-se possível de efetivá-la. Assim, o binômio espaço e tempo ganharia uma conotação mais marcante e o ensino de Geografia mais valorizado!

\section{REFERÊNCIAS}

1. $A B^{\prime}$ SABER, A. N. Um conceito de Geomorfologia a serviço das pesquisas sobre o Quaternário. Geomorfologia. São Paulo: IGEOG-USP, no 18, 1969.

2. . Os Mecanismos da Desintegração das Paisagens Tropicais no Pleistoceno. InterFacies, IBLCE - UNESP, n. 4,1979.

3. . Os domínios de natureza no Brasil: potencialidades paisagísticas. São Paulo: Ateliê Editorial, 2003.

4. BACCI, D. ; OLIVEIRA, L. y POMMER, C. Contribuição da abordagem geocientífica no ensino fundamental: tempo geológico, origem do petróleo e mudanças ambientais. Enseñanza de las Ciencias, Número Extra VIII. Congresso Internacional sobre Investigación en Didáctica de las Ciencias, Barcelona, pp. 3459-3463, 2009.

5. BERTOLINI W. Z.; VALADÃO R. C. A abordagem do relevo pela geografia: uma análise a partir dos livros didáticos. Terræ Didática, 5 (1):27-41, 2009. Disponível em <http://www.ige.unicamp.br/terraedidatica/>. Acesso em 20 out 2012.

6. BONITO, J. et al. A complexidade do tempo geológico e a sua aprendizagem com alunos portugueses (12-13 anos). São Paulo: Terræ Didática, 7():60-71, 2005. Disponível em <http://www.ige.unicamp.br/terraedidatica/>. Acesso em 30 set 2012. 
7. BRASIL. Parâmetros Curriculares Nacionais: Geografia. Brasília: MEC/ Secretaria de Educação Fundamental, 1998

8. BULFINCH, T. O livro de ouro da mitologia: histórias de deuses e heróis (a idade da fábula): Tradução de David Jardim Junior. 26. ed. Rio de Janeiro: Ediouro Publicações, 2002.

9. CLAUDINO-SALES, V.C. Sistemas ambientais e Geografia: análise crítica. In: Espaço e tempo. São Paulo: GEOUSP, $2004 . \quad$ Disponível em <http://ensciencias.uab.es/congreso09/numeroextra/art-3459-3463.pdf>. Acesso em 22 set 2012.

10. EICHER, Don. L. Tempo geológico. Rio de Janeiro: Edgard Blücher, 1996.

11. IBGE. Manual técnico de Geomorfologia. (Série Manuais técnicos em geociências, 5.) Rio de Janeiro: IBGE, 1995.

12. LIMA, C.C.U. O neotectonismo na costa do Sudeste e do Nordeste brasileiro. Revista De Ciência \& Tecnologia. № 15 - pp. 91-102: UNIMEP, 2000.

13. MONBEIG, P. Papel e valor do ensino da Geografia e de sua pesquisa. Boletim Carioca de Geografia, ano VII, 1954, $\mathrm{n}^{\text {os. }} 1$ e 2.

14. PEULVAST, J.P.; CLAUDINO SALES, V. Aplainamentos e Geodinâmica: revisitando um problema clássico em Geomorfologia. Mercator, vol. 1, 2002, p. 112-152.

15. ROSSATO. M.S. e SUERTEgARAY, D. M. A. Repensando o Tempo da Natureza em Transformação. Ágora (UNISC), Santa Cruz, v. 6, n. 2, 2000. p. 93-98.

16. SALGADO-LABOURIAU, M. L. História Ecológica da Terra. 2. ed. São Paulo: Edgard Blücher,1994.

17. SANTOS, M. Metamorfose do espaço habitado. São Paulo: Hucitec, 1988.

18. SILVA, D. L.M. da. A Geografia que se ensina e a abordagem da natureza nos livros didáticos. 2004. Dissertação de Mestrado. Pós Graduação em Geografia, UFRGS.

19. SILVA, M. L. A Dinâmica de Expansão e Retração de Cerrados e Caatingas no Período Quaternário: Uma Análise Segundo a Perspectiva da Teoria dos Refúgios e Redutos Florestais. Revista Brasileira de Geografia Física 01, 2011.VENTURI, A.L.B. Ensaios Geográficos. São Paulo: Humanitas, 2008.

20. VITTE, A. C. Por uma Geografia híbrida: ensaios sobre os mundos as naturezas e as culturas. 1․ ed. Curitiba, PR: CRV, 2011. 